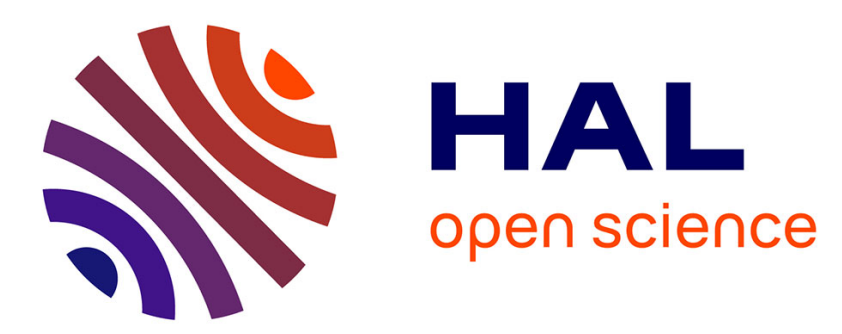

\title{
Analysis of Different Defect Configurations in CEBG Structures for Directive Patterns
}

\author{
Arezou Edalati, Tayeb Denidni, Halim Boutayeb
}

\section{To cite this version:}

Arezou Edalati, Tayeb Denidni, Halim Boutayeb. Analysis of Different Defect Configurations in CEBG Structures for Directive Patterns. IEEE Antennas and Propagation Society International Symposium 2007, Jun 2007, Honolulu, United States. pp.185-188. hal-00156633

\section{HAL Id: hal-00156633 https://hal.science/hal-00156633}

Submitted on 22 Jun 2007

HAL is a multi-disciplinary open access archive for the deposit and dissemination of scientific research documents, whether they are published or not. The documents may come from teaching and research institutions in France or abroad, or from public or private research centers.
L'archive ouverte pluridisciplinaire HAL, est destinée au dépôt et à la diffusion de documents scientifiques de niveau recherche, publiés ou non, émanant des établissements d'enseignement et de recherche français ou étrangers, des laboratoires publics ou privés. 


\title{
Analysis of Different Defect Configurations in CEBG Structures for Directive Patterns
}

\author{
Arezou Edalati*, Tayeb A. Denidni, and Halim Boutayeb \\ INRS-EMT, University of Quebec, Montreal, Canada. \\ edalati@emt.inrs.ca
}

\section{Introduction}

Electromagnetic bang Gap (EBG) materials are periodic structures characterized by forbidden propagation of electromagnetic waves in their band-gap and by the ability to open localized modes inside the band-gap by introducing defects [1-2]. Cylindrical Electromagnetic Band Gap (CEBG) structures are radially and circularly periodic, and they present pass-band and stop-band to cylindrical electromagnetic waves [3]. By applying a horn-shaped defect in these structures, it has been shown that a reconfigurable directive pattern can be obtained [4-6]. In [4], experimental results for a reconfigurable CEBG-based antenna have been presented, whereas in [5], an analysis of the transmission coefficient of CEBG structures and experimental results for a CEBG directive antenna have been proposed. In [6], a new defect configuration has been proposed for reducing the power supply, but this solution leads to a narrower band. In this paper, new defect configurations are analyzed in order to reduce the number of active elements and the required power supply in CEBG-based agile antennas. The solution with the widest bandwidth is indicated.

\section{Numerical results}

Figure 1 presents a CEBG structure without defect and Fig. 2 shows different defect configurations. Using the Finite Difference Time Domain (FDTD) method, numerical simulations were carried out to obtain the radiation patterns of the CEBG structures with defect.

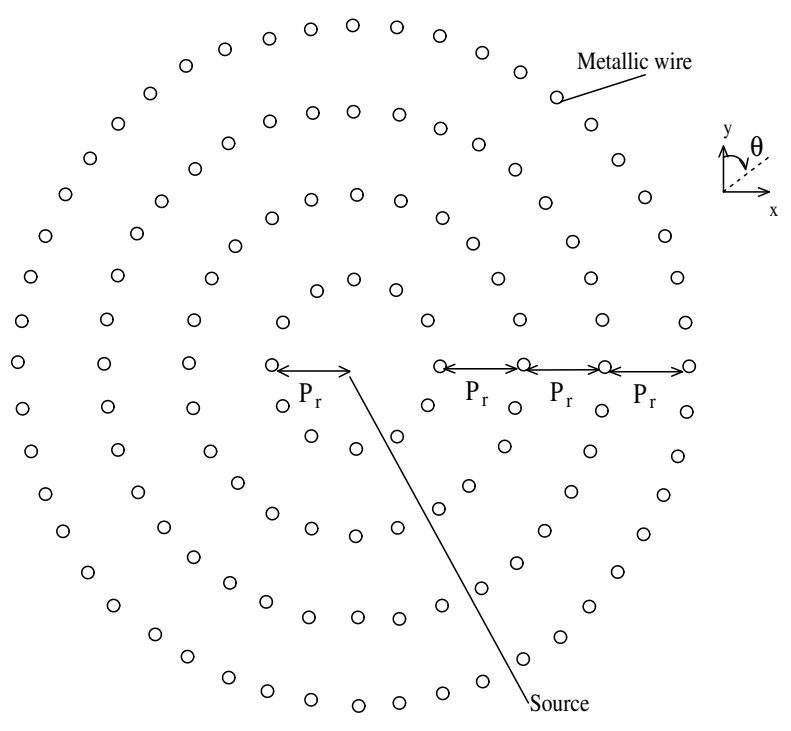

Figure 1: CEBG structure without defect composed of four cylindrical layers of metallic wires.

The structures are composed of infinite long metallic wires and are excited in their 
center with a current line source. The defect are created by introducing discontinuous wires in an initial continuous wire structure. The parameters of the CEBG structures are the followings: the radial period is $P_{r}=30 \mathrm{~mm}$, the wire diameter is $a=2 \mathrm{~mm}$, the finite wires are $15 \mathrm{~mm}$ length, and the vertical distance between two wires is 5 $m m$.

For the different cases, the far-field proprieties are investigated through an examination of the two-dimensional directivity :

$$
D_{C E B G}=10 \log \left(\frac{2 \pi\left|E_{z}(\theta=0)\right|^{2}}{\int_{0}^{2 \pi}\left|E_{z}(\theta)\right|^{2} d \theta}\right)
$$

where $E_{z}$ is the transverse component of the total electric field in the far region, calculated with the FDTD method.
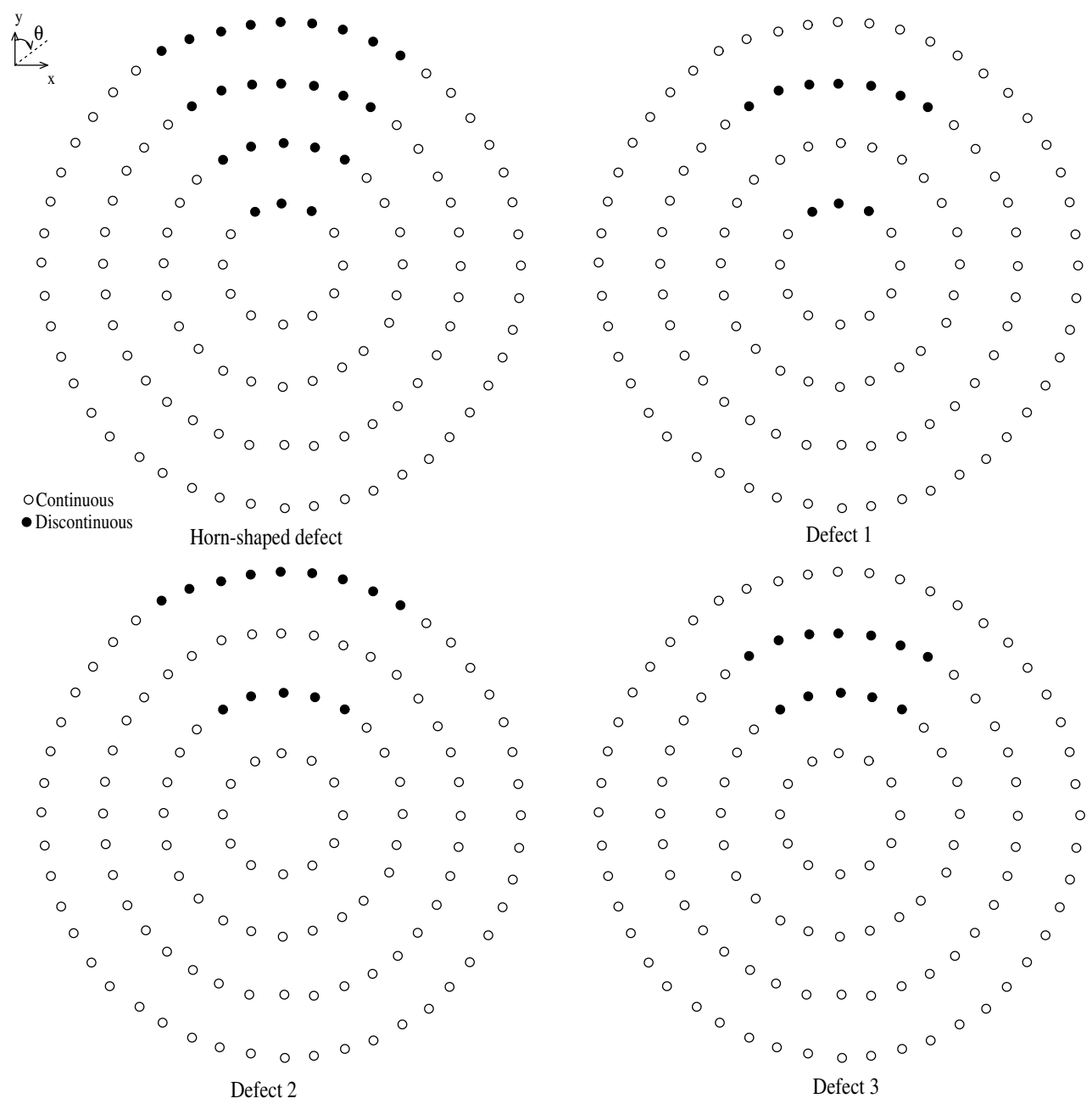

Figure 2: CEBG structures with different defect configurations

Figure 3 shows the computed directivity for the horn-shaped defect configuration, and the configurations with Defect 1 and Defect 2 (cf. Fig. 2). In the stop-band of the CEBG structure without defect, the horn-shaped defect configuration presents the same directivity as an H-plane sectorial horn antenna having the same shape than the defect (the demonstration is not shown here). Thus, this configuration is used as a reference. From Fig. 3, the configurations with Defect 1 and Defect 2 present the same directivity characteristics as the horn-shaped defect configuration 
near the frequency $1.6 \mathrm{GHz}$. At this frequency, the radiation patterns for the different configurations are plotted in Fig. 4, showing that the three configurations presents similar radiation characteristics at $1.6 \mathrm{GHz}$. Figure 5 shows the computed directivity for the horn-shaped defect configuration, and the configuration Defect 3 (cf. Fig. 2). From these curves, the configuration Defect 3 gives a larger band where its directivity concorde with the directivity of the horn-shaped defect configuration.

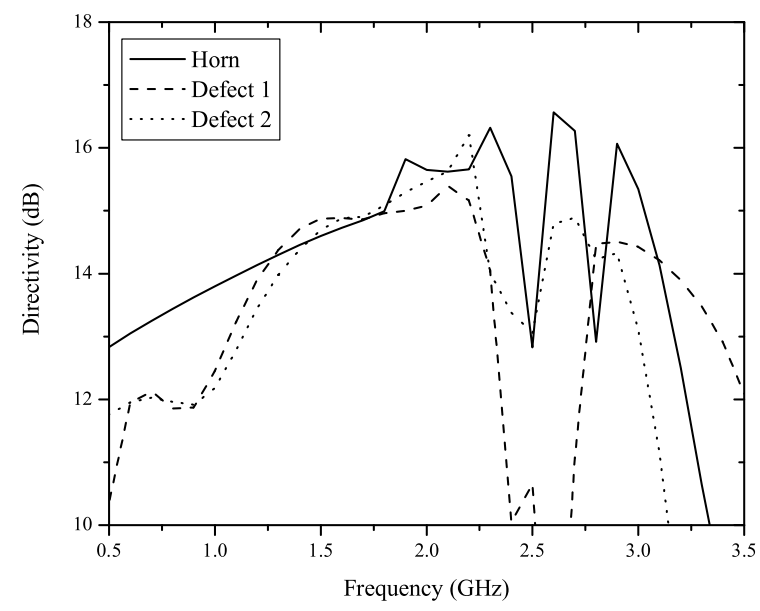

Figure 3: Directivity of the CEBG structures with different defect configurations

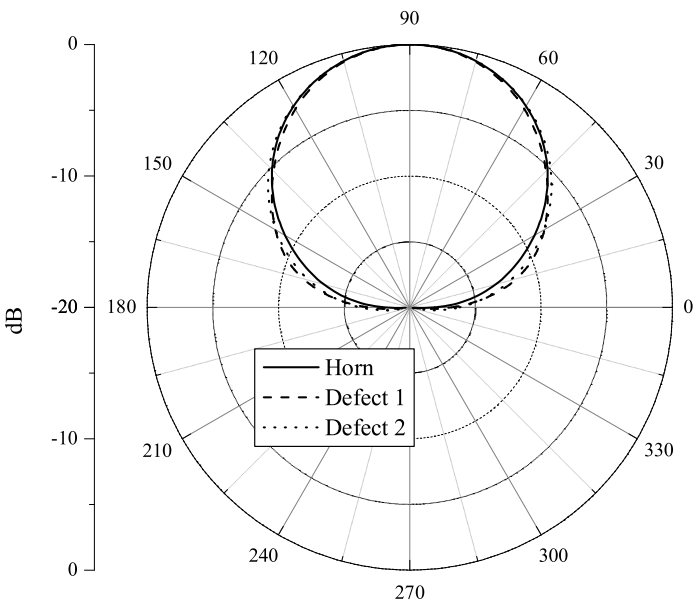

Figure 4: Radiation patterns at $1.6 \mathrm{GHz}$ for different defect configurations

For agile antenna applications, the configuration with Defect 3 allows to reduce not only the power supply but also the number of active elements. Indeed, only the second and the third layers will contain active elements, and the first and the fourth layers will be constituted by continuous wires acting as parasites without active elements. Thus, the number of active elements and the power supply are reduced by $50 \%$ compared to the solution presented in [5]. Note that the solution proposed in [6] doesn't allow to reduce the number of active elements and is more narrower band than the present solution. 


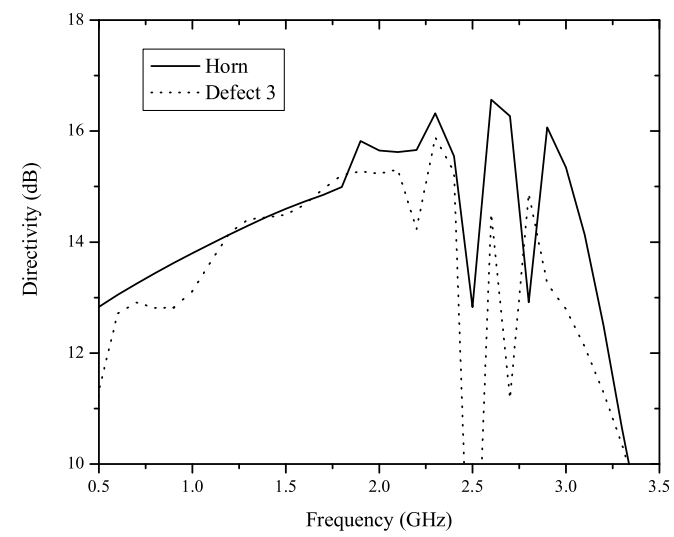

Figure 5: Directivity of the CEBG structures with different defect configurations

\section{Conclusion}

New defect configurations in Cylindrical Electromagnetic Band Gap (CEBG) structures, for beam-switching antennas applications have been tested numerically. It has been shown that it is possible to reduce the number of active elements and conserving the same directivity characteristics in a wide band as in the CEBG structure with a horn-shaped defect.

\section{Acknowledgment}

The authors gratefully acknowledge the support of this research from NSERC and Ultra-Electronics.

\section{References}

[1] J. Joannopoulos, R. D. Meade and J. N. Winn, Photonic crystals: molding the flow of light, Princeton Univ. Press, 1995.

[2] N. Engheta, R. W. Ziolkowski, Eds., Metamaterials: physics and engineering explorations, Wiley-IEEE Press, Piscataway, NJ, 2006.

[3] H. Boutayeb, K. Mahdjoubi, and A.C. Tarot, "Analysis of radius-periodic cylindrical structures", in Proc. IEEE AP-S Int. Symp. Dig., vol. 2, pp. 813- 816, June 2003.

[4] P. Ratasjack, T. Brillat, F. Gadot, P.Y. Garel, A. de Lustrac, H. Boutayeb, K. Mahdjoubi, A.C Tarot, and J.P. Daniel, "A reconfigurable EBG structure for a beam steering base station antenna", JINA, Nov. 2004.

[5] H. Boutayeb, T.A. Denidni, K. Mahdjoubi, A.-C. Tarot, A. Sebak and L.Talbi, "Analysis and Design of a Cylindrical EBG-based directive antenna", IEEE Trans. Ant. Propag., vol.54, pp. 211-219, Jan. 2006.

[6] H. Boutayeb and T.A. Denidni, "Technique for Reducing the Power Supply in Reconfigurable Cylindrical Electromagnetic Band Gap Structures", IEEE Ant. Wir. Prop. Lett., vol. 5 , pp. 425-425, 2006. 